\title{
Corporate Management Structure of Large Malaysian Construction Companies
}

\author{
Hamimah Adnan \\ Faculty of Architecture, Planning and Surveying \\ Universiti Teknologi MARA \\ Shah Alam Selangor, Malaysia \\ Tel: 60-3-5544 4306 E-mail: hamimah689@salam.uitm.edu.my \\ Hj. Kamaruzaman Jusoff \\ Yale University, Tropical Resources Institute \\ School of Forestry \& Environmental Studies \\ 210 Prospect St, New Haven, CT 06511, USA \\ Tel: 203-676-7761Ｅ-mail: jusoff.kamaruzaman@yale.edu
}

\begin{abstract}
The aim of this study is to explore the parent company of large construction companies managing their local subsidiaries in Malaysia. The research is based on a set of questionnaire survey that was distributed to Chief Operating Officers, Executive Director, Senior and General Managers registered under the Construction Industry Development Board Malaysia. The purpose of the questionnaire is to highlight the existence of various corporate management styles in the companies and their subsidiaries. The study found that construction firm need to develop a long-term vision of its strategic intent and need to upgrade productivity and have new technology. Parent companies need to maintain quality products to clients to projecting sound track record. Construction companies need o provide quality services to meet their client's in formulation and implementing corporate strategies and business plan. They need to explore new construction technology to have competitive the edge in the market and they have to expand for regional expansion for higher business growth and synergies diversification to broaden revenue source, marketing plan and expand overseas markets.
\end{abstract}

Keywords: Corporate Management, Structure, Large Malaysian Construction Companies 


\section{Introduction}

The world market of today is characterized by a move towards globalization, escalating requirements for research and development, increased sophistication of new products and rapid technological obsolescence that shortens the product life cycle. These trends are forcing companies to re-examine the feasibility and wisdom of traditional market development methods and market positioning strategies (Hung, 1992). In most business today, diversification is one of the most important strategies adopted (Porter, 1980). Prahalad and Doz (1981) said that most parent companies have increasingly benefited from the larger share of sales and profits through the expansion and diversification of parent companies carried out through acquisition of subsidiaries and contended that parent companies transfer their assets to those potential and high priority subsidiaries, especially if the subsidiary is enjoying higher growth.

Mulcahy (1990, p12) observed that, to be successful, a construction company "must have clear objectives recognizing the markets it wishes to address, services it will provide, risks it will carry, structure it will use, the environment it will operate within, controls it will put in place and returns it wishes to achieve. The current contracting business in construction is facing tough and challenging times ahead due to tough competition. The demand in construction is cyclical and it is rare for one construction companies to undertake only one particular type of construction though some may be specialists in a specific area of construction. When firms grow bigger they tend to diversify into a range of construction types and also in various geographical regions (Mohd Ali, 1995). Contractor and Lorange (1988) suggested that strategic alliances are manifestations of globalization.

Corporate strategy can be seen as the linking process between the management of the organization's internal resources and its external relationships with its customers, suppliers, competitors and the economic and social environment in which it exists. The organisation develops these relationships from its abilities and resources. Hence, the organisation uses its history, skills, resources, knowledge and various concepts to explore its future actions. The industry environment is the set of factors that directly influences a firm and its competitive actions and competitive response; the threats of new entrants, the power of suppliers the power of buyers, the threat of product substitutes and the intensity of rivalry among competitors. An opportunity is a condition in the general environment that if, exploited helps a company achieve strategic competitiveness. A threat is a condition in the general environment that may hinder a company's efforts to achieve strategic competitiveness. The resources of an organisation include its human resource skills, the investment and the capital in every part of the organisation. Organisations need to develop corporate strategies to optimise the use of these resources. In particular, it is essential to investigate the sustainable competitive advantage that will allow the organisation to survive and prosper against competition. In this context environment encompasses every aspect external to the organisation itself: not only the economic and political circumstances, which may vary widely around the world, but also competitors, customers and suppliers, who may vary in being aggressive to a greater or lesser degree - customers and competitors are particularly important here. 
Corporate strategy provides value for the people involved in the organisation - its stakeholders - but it is often the senior managers who develop the view of the organisation's overall objectives in the broadest possible terms. They conduct an examination of the objectives and the organisation's relationship with its environment. They will also analyse the resources of the organisation. To be successful, the strategy is likely to be built on the particular skills of the organisation and the special relationships that it has or can develop with those outside suppliers, customers, distributors and government. For many organisations, this will mean developing advantages over competitors that are sustainable over time. There are usually many options available and one or more will have to be selected. There need to be a strategy implementation where major difficulties in terms of motivation, power relationships, government negotiations, company acquisitions will be involved. A strategy that cannot be implemented is not worth the paper it is written on. Diversification strategy reflects the heterogeneity of activities within the corporation and so long a company has its hands full trying to capitalize on profitable opportunities in its present industry, there is no urgency to pursue diversification. Diversification also had to be considered when a firm possesses technological expertise, core competencies and resources strengths that are uniquely well suited for competing successfully in other resources (Thompson and Strickland, 2001). Mazelan (2000) contended that in diversifying, parent companies may expand their portfolios through acquisition or mergers, and local subsidiaries may or may not be in the same business as their parent company. This means that before a company diversifies, it must have a reason for diversifying, choose its own direction to diversify, and also select the mode of diversification.

Decisions about what business to include in the corporate portfolio and how to allocate resources among the businesses are key corporate: strategy issues for all multi-business companies (Goold and Luchs, 1996). Teece (1996) said that a specialised firm's generation of excess resources, both managerial and technical, and their fungible character is critical to the theory of diversification. The resource-base theory of the firm emphasises the importance of a firm's tangible and intangible resources, and suggests that firms should diversify into new products and in businesses in order to make full use of their resources (Goold and Luchs, 1996). They argued that the resource-base theory of the firm implies that a multi-business firm should seek to achieve synergies across its businesses and will achieves synergies if the sharing of activities or skills enables such businesses to perform better and a firm is more than simply the sum of its parts, and the achievement of synergy has been a goal of many corporate strategies. Prahalad and Hamel (1996) argued the real strength of a corporation is its skills and know-how, and that a firm should aim to exploit these assets in new areas. They further argue that the key resources of a corporation is its core competencies, or its expertise in particular technologies with the end products of the different businesses can vary widely, the separate businesses can share and contribute to the core competencies of the corporation. This approach is the key to a successful corporate strategy. They contended that by identifying and exploiting the opportunities for sharing activities or core competencies across different business will managers achieve the goal of making him multi-business company more then simply sum of its parts. Corporate management is the intermediate between shareholders and the managers of potentially separable businesses within the corporate 
portfolio. Planning influence and control influence (Goold and Campbell, 1987) are two important elements in strategic management. Most of the roles and responsibilities for the successful management of business units and subsidiary companies are related to their own established practices of strategic management to achieve their corporate mission and objectives.

Strategic planning is a tool used by parent companies in gaining influence over their subsidiaries so that implementation of identified strategies can be effective and efficiently carried out throughout the whole organisation without much hassle. Strategic planners should not be too engrossed in the processes of strategic management but should use them as tools or assets, not only in helping to design strategies, but more to help the strategies become commitments of the people implementing them. Therefore, parent companies must use certain influence tactics in order to get their subsidiaries' commitment. Parent companies also play the role of decision maker. According to Reid (1989) experience with major corporations demonstrates that they frequently make monumental mistakes. It can be attributed directly or indirectly to ineffective strategic planning and management. Most of the critical decisions made by parent companies are related to performance and investment decisions. Chandler (1991) said that those corporate executives not only monitor the current performance of their several businesses but also determine and implement investment in facilities and personnel required for future production and distribution in the different product and geographical markets they serve. Most companies have their own organisation designed in such a way that it will meet their objectives with the strategy adopted. There must be a fit between the strategy adopted and the design of the organisation. The organisational design creates the capabilities and skins for parent companies to achieve the company's objectives. The capabilities and skills in managing business units and subsidiaries by parent companies touch the issues of inter-organisational relationship, i.e. headquarters-subsidiary relationship.

Prahalad and Doz (1981) mentioned that headquarters must not only co-ordinate the operations of subsidiaries but must increasingly influence the direction of subsidiary strategy. They argued that head office faced with an ability to exert control over the subsidiaries on the basis of the subsidiaries' dependence on strategic resources, must find substitute mechanisms. Creating a sophisticated organisational context - a blending of organisational structure, information systems, measurement and reward systems, and career planning and a fostering of common organisational culture - can compensate for the erosion of head office's capacity to control subsidiaries. This would facilitate the relationship between (he head office and subsidiaries such that the head office can continue to influence and monitor subsidiary strategy. Effective headquarters influence in shaping global competitive strategy requires not only changes in cognitive and strategic orientation but also shifts in the thrust of resource allocation choices. This in turn, requires changes in power within the organisation. Effective implementation of new programs implied by changed resource allocation choices usually requires changes in administrative control mechanisms. In other words, all four orientations have to change if headquarters control is to be effective. They argued that the mechanisms used may vary from company to company. In choosing the mix of mechanisms to be used and the ordering and timing of their introduction, top managers must consider the characteristics 
of these mechanisms. Doz and Prahalad (1981) conclude that the need for substantive control (or the ability to achieve such control given environmental conditions) varies between industries as it also varies with the competitive position of a firm in its industry. These differences, based on industry characteristics and competitive positions, make a careful differentiation between businesses of diversified multinational necessary.

In the study of inter-organisational relationships between headquarters and subsidiaries, one factor that could help builds up parent companies' capabilities and skills is the administrative mechanism. In their study on multinational companies, Mazelan (2000) argued that strategies create different implementation requirements and therefore the administrative systems and capabilities of the organisation must be designed to fit these requirements. Therefore, parent companies that have the roles and responsibilities to implement corporate strategies throughout the whole organisation must utilise various administrative mechanisms to achieve the desired corporate objectives. Corporate management behaviour should be differentiated into different categories based on the joint conditions of (1) the different extent of 'planning influence', (2) the different extent of 'control influence', (3) different extents of external environmental conditions, and (4) different extent of administrative mechanism used. Hence, various types of corporate management styles can be highlighted based on the different practices of corporate management on these four factors or dimensions. Goold and Campbell (1987) have described eight types of strategic management styles based on two dimensions only, that is, 'planning influence' and 'control influence'. In grouping or classifying companies into various types of corporate management styles, the author can use all the four dimensions, or any selected few mentioned above. The classifying of organisations for their corporate management behaviour based on any combination of the four dimensions i.e. planning influence, control influence, environmental condition and administrative mechanism is still not fully explored.

While the government is geared to create a conducive environment for the construction companies with incentives, tax exemption and structural facilities, the corporate managers of Malaysian construction companies not only have to comply with the government policies but must also steer their organisations properly to be successful. Therefore, in their effort to expand and diversify their businesses, corporate managers must know how to manage their subsidiaries and business units efficiently and effectively. The study of local companies is different from the study of foreign companies. Very little has been written about the management of local subsidiaries in Malaysia especially in the construction industry. Therefore, this research aims to understand how Malaysian parent companies manage their local subsidiaries, using the companies in the construction sector as the research sample. The overall objective of this research is to explore the parent company of large construction companies managing their local subsidiaries through planning and controlling in Malaysia.

\section{Malaysian Construction Industry}

\subsection{Construction Industry Outlook 2000-2005}

The performance of construction sector is expected to turn around with value added growing by $3.1 \%$ in 2000 (1999: -5.6\%). The growth is mainly due to the implementation of several 
large public and privatized infrastructure projects and new investment in the residential sector, in particular, low and medium-cost houses to meet underlying demand. Excess supply, however, still exists in several segments of the property market. In the non-residential sector, the oversupply situation and low occupancy rates for office and retail space continue to dampen building activities are expected to remain strong. Civil engineering activities are expected to continue to recover and strengthen given the fiscal stimulus and resumption of projects that were deferred. Consequently, the share of the construction sector overall GDP is estimated at $3.4 \%$ (1999: $3.6 \%$ ).

Construction related industries are expected to benefit from the ongoing implementation of fiscal stimulus project as well as sustained performance of the housing sub-sector. On the whole, the industry recorded a growth of 5.5\% (January-June 2001: 10\%). Cement and concrete continued to record a positive growth of 13.1\% (January-June 2001: 18.4\%). Demand is estimated to grow stronger this year, partly aided by the increased utilization of cement and several ongoing and plan public infrastructure projects to be implemented in 2002/2003. Similarly, product of ceramic and tiles also expanded by $4.1 \%$ during the first six month to meet increasing demand from the housing sub-sector. Currently, the non-metallic mineral industry especially the ceramic produces, are operating above $80 \%$ capacity. Likewise, the iron and steel industry is generally expected to perform better due to the positive effects of fiscal stimulus as well as better external demand. As a result, capacity utilization is expected increase to over 65\% compared to 55\% in 2001.

The government continued to monitor and address the issue of property over hand especially commercial space. Towards this ends, the directive to local authorities not to approve any new construction of office and commercial space, except in special cases to discourage further to property stock continuous to be enforced. During the first quarter of 2002, the number of unsold industrial unit recorded a reduction of $8.7 \%$ while vacant space in shopping complexes was reduced marginally by $1.1 \%$ compared to the last quarter of 2001 . In contrast, purpose-built offices vacancy increased marginally by $0.7 \%$ during the same period.

Construction industries recorded a firmer growth of 13.2\% (January-June 2002: 5.5\%), while the iron and steel as well as non-metallic mineral industry continued to perform better due to the continuing implementation of several public roads and low cost houses. These industries also continued to benefit from the ongoing implementation of the Package and other efforts to stimulate residential housing and public infrastructure projects. Similarly, iron and steel also recorded positive growth of 9.3\%, while cement and ready-mixed concrete recorded higher growth of $20.6 \%$ and $15.6 \%$ respectively. With external demand anticipated to grow by more than $14 \%$ this year, and the positive effect of the implementation of large socio-economic infrastructure projects, such as the hospital cum apartment of Lembaga Tabung Haji in Kuala Lumpur, Petronas Hospital, Kajang Sungai Ramai Ring Road and the new Johore-Singapore bridge, the cement and concrete industry is expected to improve further, increasing capacity utilization of the industries to above $65 \%$.

Construction activity is anticipated to pick up on account of increased activities, particularly in the residential property sub-sector and low cost housing programme. During the first half 
of 2004, the construction sector recorded a marginal decline of $0.6 \%$ largely due to lower public sector construction activity, especially in infrastructure projects. However, higher residential construction activity following stronger growth of housing starts of $36.8 \%$ during the second half of 2003 and some on-going infrastructure projects will provide sufficient support for the sector to record a positive growth of 0.5\% in 2004 (2003: 1.9\%).

\section{Methodology}

The research is based on a set of questionnaire survey that was distributed to Chief Operating Officers, Executive Director, Senior and General Managers registered under the "Grade G7" and "Grade G6" with the Construction Industry Development Board Malaysia. The purpose of the questionnaire is to highlight the existence of various corporate management styles in the G7 companies and their subsidiaries. There were eleven (11) respondents from Malay-owned companies, three (3) Chinese companies and one (1) other indigenous bumiputera. There were no Indian companies participate in this research.

The type of construction projects undertaken by companies was noted in order to provide background information on the nature of their business. Each company had undertaken more than one type of project and they are ranked from the highest at the top to the lowest. There are seven (7) respondents with nineteen (19) percent from the residential building contractor, twelve (12) respondents consist of contractor from the non residential building with thirty two percent (32) percent from the civil engineering contractor, two (2) from the housing developer, one (1) respondent from the specialist sub-contractor, three (3) respondents from the project manager and three form the plant and machinery supplier. There are ten (10) companies with the age of 5 years, five (5) companies with the age of 10 - 15 years, ten (10) companies with more than 15 years. There are twenty (20) parent companies from the local company. There are twelve (12) parent companies with four (4) subsidiaries and one (1) stand alone. There are twenty (20) local companies in the parent company and five (5) foreign subsidiaries in the parent company. There are seven (7) companies that were wholly owned by a single organisation. Three (3) with over fifty percent (50\%) owned by a single organisation and the rest dispersed. Two (2) companies with over $10 \%$ but less than fifty percent owned by single organisation and the rate dispersed. There are nine hundred fifty eight (958) numbers of employees at the parent company, one thousand seven hundred sixty one (1761) employees at the subsidiary and thirty (30) employees for stand alone.

\section{Results and Discussion}

From the questionnaire surveys, it could be seen that profit, cooperation, quality of works, time of completion, increased project scale, skill and experience, knowledge information, business expansion and coordination of works are the subsidiary's highest priority. From the findings, cooperation, knowledge information, better risk management, management of resources, profit, financial collaboration, technology transfer, coordination of works received the parent highest priority. It was found that this construction companies were committed to provide quality services to meet their client's satisfaction. They conduct their business responsibilities with proper coordination and cooperation to achieve on time. They also need to achieve on time and project completion to enhance training to continual improvement. 
Cooperation occur when people or groups act together in a coordinated way to pursued shared or complementary goals. - as opposed to competitions, where the emphasis is on winning and outdoing others because the parties believe that ones goal attainment interferes with the other goals (Argyle, 1992). Cooperation has also been positively linked to the performance at the organisational level (Pearce 2001). Companies would tighten supervision and provide latest information and public relation and confirmed that they will get $100 \%$ involvement in formulation and implementing corporate strategies and business plans.

This study found that just as corporate plans can be used to indicate corporate strategies, business plans can also be useful to highlight the strategies of each business. With a proper business plan indicate the commitment of corporate management in insisting on formal planning at their business unit or subsidiary level. The researcher found that the companies with different corporate management, revealing their different approaches in the implementation of strategic planning. However, some of the parent companies prefer their subsidiaries to do their own planning. Commitments from subsidiaries to come out with their own business plans are expected. Most parent companies experience that their subsidiaries fall back on their centre for guidance and support. This study confirmed that most of the corporate management have understood the concept of the changing business environment and the need to change strategies when and where required by the situation they are in. Business plans are developed to achieve the business unit's or subsidiary objectives.

Company A hope to maintain quality products to clients to projecting sound track record. They said that they had to explore new construction technology to have competitive the edge in the market and they have to expand for regional expansion for higher business growth and synergies diversification to broaden revenue source, marketing plan and expand overseas markets. They believe that their strengths lie in their positive attributes and strong corporate values that they strive to translate into the running of their business. They have their employee commitments and loyalty of their employees who are the backbone of their company. Since they involved in property business, their successful marketing strategy in the property business is to understand the market, understand what the customers want and build them. Company B and C hope to offer and deliver products that are market-driven to discerning purchasers. They are hoping to go into niche developments to cater for today's changing market demands. Company's innovation is developed through research and developments (R and D). Firms can produce and manage incremental or radical innovation. They build on existing knowledge bases and provide small improvements in the current product line. Radical innovations usually provide significant technological breakthroughs and create new knowledge.

A firm must develop a long-term vision of its strategic intent. A long-term vision is the driver of strategic leader's behaviour in terms of the remaining four components of effective strategic leadership. Strategic leaders must ensure that their firms exploit its core competencies, which are used to produce and deliver products that create value for customers, through the implementation of strategies. In related diversified and large firms in particular, core competencies are exploited by sharing them across units and products. Companies 
would need to upgrade productivity and have new technology. This is important because they would prefer to keep overhead low call for voluntary service scheme to save the company. Knowledge (information, intelligence and expertise) is the basis of technology and its application. Knowledge is critical organisational resource and is increasingly a valuable sources of competitive advantage. In order to survive in the competitive world and capture intelligence, firms must develop through training programs and acquire ( e.g. by hiring educated and experienced employees) knowledge, integrate it into the organisation to create capabilities and then apply it to gain a competitive advantage. Thus, firms must develop a program whereby they learn and then integrate this learning into firms operations.

It is suggested that a strategic alliance is a cooperative strategy in which firms combine some of their resources and capabilities to create a competitive advantage. Thus, as linkages between, strategic alliances involve firms with some degree of exchange and sharing resources and capabilities to co-develop or distribute goods or services. Strategic alliances let firms leverage their existing resources and capabilities while working with partners to develop additional resources and capabilities as the foundation for new competitive advantages. A joint venture is a strategic alliance in which two or more firms create legally independent company to share some of their resources and capabilities to develop a competitive advantage. Changing a firm's organisational firm's organisational culture is more difficult than maintaining it, but effective strategic leaders recognise when change is needed. Incremental changes to the firm's culture typically are used to implement strategies. Shaping and reinforcing a new culture require effective communication and problem solving, along with the selection of the right people with those who have the values desired for the organisation and with effective performance appraisals) establishing goals and measuring individual performance towards goals that fit in with the new core values) and appropriate reward systems (rewarding the desired behaviours that reflect the new core values)

Downsizing is a reduction in the number of a firm's employees and sometimes in the number of its operating units, but it may or may not change the composition of businesses in the company's portfolio. Some of the company would send for staff international skills improvement and short term survival with long term sustainable entity. They have the human relationship and public relation and good communication to project. Company will employ skilful personnel's and to get the best through experience and to achieve less than five non compliance project per year. They would like to ensure vendor or sub-con performance achieve the satisfactory stage and to meet on time project completion. They would provide quality services to meet client satisfaction and generate meeting for effective communication and coordination. In order to control subsidiaries, parent companies must monitor subsidiaries performances closely. Most of the companies in the sample are expected to have set some form of performance indicator to monitor their subsidiaries' performances. Parent companies have their own way of rewarding local subsidiaries' performances. The ever changing environment is also important for the companies on the SWOT analysis, i.e. Strength, Weakness, Opportunities and Threat.

SWOT analysis is grounded in the basic principles between a company's resource capability (as reflected by its balance of resources strengths and weaknesses) and its external situation 
(as reflected by industry and competitive conditions, the company's profitability and market standing). Companies would emphasis on their four pillars of strength,i.e. customer capital. This factor is important to satisfy their customers have been a core focus in their business. Secondly, organisational capital where the quality systems and procedures, i.e. ISO accreditations and vision enable their people to innovate, shape lifestyles and stay customer-focused continue to propel the company forward. They suggested that their good relationship with contractors, suppliers and service providers has enabled both parties to enjoy better economies of scale, quality, timely delivery and smoother approvals. The company is hugely supported by its focus. The contractors stressed that the quality staff performance and transparency is very important in the operation and management teamwork.

\section{Conclusion}

From the findings, it was found that companies understand on the implementing of corporate management. Profit, cooperation, quality of works, time of completion, increased project scale, skill and experience, knowledge information, business expansion and coordination of works are the subsidiary's highest priority. Cooperation, knowledge information, better risk management, management of resources, profit, financial collaboration, technology transfer, coordination of works received the parent highest priority.

Construction companies need o provide quality services to meet their client's in formulation and implementing corporate strategies and business plan. They need to explore new construction technology to have competitive the edge in the market and they have to expand for regional expansion for higher business growth and synergies diversification to broaden revenue source, marketing plan and expand overseas markets. Companies would need to upgrade productivity and have new technology. It is suggested that a strategic alliance is a cooperative strategy in which firms combine some of their resources and capabilities to create a competitive advantage such as joint venture.

\section{References}

Argyle, M. (1992). Corporation: The Basis of Sociability, London, Routledge.

Campbell, A. (1994). Managing diversification and business development, Long Range Planning, Vol. 22, pp.128-130.

Chandler, A.D. (1991). The functions of HQ Unit in the Multibusiness Firm, Strategic Management Journal, Vol.12, pp.31-50.

Chinoswsky, P.S and Associate Member, ASCE and Meredith, J.E (2000) Strategic Management in Construction, Journal of Construction Engineering and Management, January/February, pp 1-9.

Contractor, F.J and Lorange, P. (1988). Why should firms cooperate? The strategy and economic basis for cooperative ventures, In Contractor F.J.

Doz, Y.L and Prahalad, C.K. (1981). Headquarters influence and strategic control in MNCs, Sloan Management Review, pp15-29. 
Goold, M.A, and Campbell, A. (1987). Strategies and Styles: The Role of the Centre in Managing Diversified Corporations, Oxford: Basil Blackwell.

Goold, M.A and K.S Luchs. (1996). Managing the Multibusiness Company: Strategic issues for diversified groups, London, Routledge.

Hung, C.L. (1992). Strategic business alliance between Canada and the newly industrialised countries of Pacific Asia, Management International Review, Oct.

Lorange, P. (eds). Cooperatives Strategies in International Business, Lexington Books, Lexington, pp.3-30.

Mazelan, N.A. (2000). Corporate Management Styles, Case Study of Malaysian Companies, Pelanduk Publication.

Mulcahy, J.F. (1990). Management of the Building Firm, Proceedings,CIB 90, Joint Symposium on Building Economics and Construction Management, Sydney, March, Vol.6, pp.11-21.

Mohd Ali, M.Y.I. (1995). A Critical investigation on UK Joint Venture Projects, Unpublished Phd Thesis, Loughborough University.

Porter, M.E. (1980). Competitive strategies.Techniques for Analysing Industries and Competitors, New York. Free Press.

Prahalad, C.K and Hamel, G. (1996). The core competence of the corporation, In M. s (eds), Managing the Multibusiness Company, PP.218-239, Routledge, London.

Pearce, R.J. (2001). Looking inside the joint venture to help understand the link between inter-parent cooperation and performance, Journal of Management Studies, 38:4 June 2001.

Rashid, A.A. (1991). Global Strategies of construction firms, Unpublished PhD Thesis, University of Reading, UK.

Reid, D.M. (1989). Operationalizing strategic planning, Strategic Management Journal.

Strassman, W.P and Wells, L. (1988) .The Global Construction Industry: Strategic for Entry, growth and survival, Unwin Hyman, Boston.

Teece,D.J. (1996). Economics of scope and the scope of the enterprise, Journal of Economic Behaviour and Organisation, Vol. 1, pp. 223-247.

Thompson, A. and Strickland, A. (1987). Strategic Management $\left(4^{\text {th }}\right.$ Ed). Plano: YX: Business Publications. 